\title{
O USO DE TECNOLOGIAS DA INFORMAÇÃO - TIC COMO FERRAMENTAS NO PROCESSO ENSINO APRENDIZAGM DE CIÊNCIAS
}

\author{
Maristela Gonçalves Giassi ${ }^{1}$ \\ Mariana Colombo Ramos ${ }^{2}$ \\ Beatriz Reiser Tramontin ${ }^{3}$
}

\section{INTRODUÇÃO}

No mundo atual a sociedade exige que a escola esteja constantemente se atualizando, pois, os alunos estão cada vez mais conectados. A escola não tem que ser apenas um local para transferência de conteúdos, mas sim de ensino e aprendizagem. Segundo Serafim e Souza (2008, p. 20),

\begin{abstract}
A escola de hoje é fruto da era industrial, foi estruturada para preparar as pessoas para viver e trabalhar na sociedade que agora está sendo convocada a aprender, devido às novas exigências de formação de indivíduos, profissionais e cidadãos muito diferentes daqueles que eram necessários na era industrial.
\end{abstract}

O mundo caminha cada vez mais em direção a inovações tecnológicas, sendo que a Tecnologia da Informação e Comunicação - TIC, tem se modificado e avançado cada vez mais, assim era esperado que houvesse mudanças significativas na educação, sendo que cada vez mais a TIC vem fazendo parte da vida do aluno.

As TIC vêm sofrendo mudanças a todo o momento, sendo muitas vezes difícil de acompanhar, pois passamos por elas muito rapidamente, o que dificulta explorar devidamente todas as suas possibilidades. Sabe-se, no entanto que o seu uso permite aproximar o aluno das atividades e dos conteúdos trabalhados em sala de aula, bem como possibilita maior interação entre eles.

Nas escolas muitos alunos sentem-se desmotivados com a forma que os professores trabalham em suas aulas. Hoje o professor tem que buscar descobrir formas que melhor se aplicam para a apresentação de cada conteúdo, pois os

Maristela Gonçalves Giassi ${ }^{1}$ - mgi@unesc.net - Professora do Curso de Ciências Biológicas da Unesc. Rua Senador Paulo Sarazate, 544. Bairro Michel. 88.803-120 Criciúma - SC

Mariana Colombo Ramos ${ }^{2}$ - marianacolombo_07@hotmail.com - Acadêmico do Curso de Ciências

Biológicas da Unesc.

Beatriz Reiser Tramontin ${ }^{3}$ - beatriz.reiser@gmail.com - Acadêmica do Curso de Engenharia Ambiental da Unesc. 
alunos querem aulas que utilizem as TIC, pois estas estão inseridas na vida fora da escola, além disso, sabemos que os jovens são os que mais rápido aderem as novas tecnologias, que eles estão sempre em busca de algo novo, sendo que estes já vêm com um conhecimento sobre tecnologias muitas vezes maior que a dos professores, assim, se faz necessário a inclusão dessas tecnologias na sala de aula. Segundo Kaieski, Grings e Fetter (2015, p. 4),

\begin{abstract}
Atualmente, as tecnologias móveis estão verdadeiramente prontas para transformar o aprendizado dentro e fora da sala de aula. É chegado o momento de as instituições educacionais, em todos os níveis, desenvolverem programas de ensino e aprendizagem voltados para o uso das tecnologias móveis, objetivando colher os benefícios da redução de custos aliada a um ensino mais eficaz, com maior aproveitamento do aluno.
\end{abstract}

O professor não pode ter medo de incluir as TIC como uma ferramenta do conhecimento, segundo Moura e Brandão (2013, p. 2 )

O uso das TIC no ambiente escolar precisa ser visto pelos professores, não como uma ameaça a sua forma de ensinar, mas como um aliado para a promoção do aprendizado, porém não esquecendo que o professor é quem determina o conteúdo e o aluno é o sujeito que manifesta o melhor caminho para poder assimila- lo.

Para o autor é de importância vital utilizar as tecnologias, desde que seja utilizada de forma consciente pelo professor, com um objetivo a ser cumprido para ajudar na construção do conhecimento do aluno.

Este cenário motivou a pesquisa que tem como objetivo investigar a eficácia do uso de tecnologias no processo de ensino e aprendizagem de Ciências.

\title{
METODOLOGIA
}

Trata-se de uma pesquisa qualitativa, exploratória e explicativa de cunho experimental. O projeto foi desenvolvido em uma escola da rede pública estadual de Criciúma - SC, com duas turmas de sextos anos do Ensino Fundamental, sendo uma experimental e a outra, controle. O tema definido pela professora para desenvolver a atividade foi o Solo. $\mathrm{Na}$ turma experimental foram realizadas atividades com o uso de TIC e na outra, foram observadas as aulas conforme a metodologia costumeira da professora. 
No primeiro momento da aplicação a bolsista buscou saber se os alunos sabiam mexer no computador, pesquisar na internet, fazer um power point, quais possuíam celular, assim pode-se dividir a sala em cinco grupos para realização das atividades. Foi feito um sorteio para ver qual tecnologia e conteúdos cada grupo iria utilizar: 1) Para o tema "Erosão e Desmatamentos", foi utilizado Câmera de celular para bater foto de desenhos feitos por eles sobre a etapa do desmatamento e pesquisa na internet, para conhecer um pouco mais sobre o tema, para montar uma sequência no programa movie maker. 2) Com o tema a "utilização do solo", os alunos pesquisaram na internet e montaram uma apresentação de power point. 3) No tema "O lixo e o solo" os alunos entrevistaram serventes falando sobre a importância de se jogar o lixo no lugar certo e como ele prejudica o solo. Nesta atividade foi montado um vídeo no programa movie maker. 4) Com o tema "O que é o solo e Tipos de Solo" os alunos pesquisaram fotos e textos na internet e montaram um power point para apresentação. 5) Para o tema "recursos naturais não renováveis do solo" foi utilizado o youtube, os alunos escolheram vídeos sobre petróleo e carvão mineral.

No primeiro momento todos os grupos foram levados para sala de informática, no segundo momento foi levado um grupo por vez, e a bolsista levou o próprio notebook, pois os computadores da escola não possuíam movie maker. No terceiro momento os alunos fizeram a apresentação dos trabalhos, valendo nota.

\section{RESULTADOS}

Os resultados confirmaram que as tecnologias, por fazerem parte da vida dos alunos, contribuíram para que a aula com a turma experimental fosse muito bem aproveitada por eles. Outro fator que também percebemos que pode ter contribuído para o bom aproveitamento da turma, pode ter sido o fato de ser algo diferente na rotina da sala de aula, envolvendo outros recursos como o uso da internet e do celular.

Durante a observação na turma controle, a professora usou para dar suas aulas o livro didático e o quadro, trabalhando de forma mais tradicional. Já na turma experimental o conteúdo foi trabalhado com as TIC, trazendo um diferencial que motivou os alunos. 
Durante a montagem dos trabalhos os alunos participaram ativamente, pesquisando na internet textos, imagens, vídeos, um dos grupos bateu fotos com o celular, outro gravou entrevistas, também com o celular, que foram feitas com funcionários da escola, juntando toda a criatividade dos alunos foi montado os trabalhos, sendo que o resultado final surpreendeu até a professora.

O primeiro grupo que trabalhou sobre erosão e desmatamento pesquisou fotos na internet e textos para poder entender o seu tema e fizeram três desenhos para demonstrar a sequência do desmatamento. Com a pesquisa, as fotos e os desenhos, os alunos montaram um vídeo, no programa movie maker, com o auxílio da bolsista, para ser apresentado em sala de aula todos os integrantes do grupo participaram.

Dois grupos trabalharam com a criação de slides no programa power point, eles também fizeram a pesquisa na sala de informática, porém como a informática trabalha com sistema Linux e não havia o programa, em uma das aulas a bolsista levou o próprio notebook para ajudar na montagem dos slides. Os alunos fizeram toda a pesquisa e a bolsista apenas ajudou na organização. Pode-se perceber que todos sabiam fazer a pesquisa no google, e se mostraram interessados, curiosos, lendo textos sobre os temas e buscando fotos, o grupo que trabalhou os tipos de solo trouxe para a sala fotos impressas para demonstrar melhor o que estavam falando, isso surpreendeu a todos por causa da iniciativa, o que chamou a atenção foi que todos os participantes dos grupos apresentaram o trabalho, eles próprios dividiram o assunto para apresentação.

Um dos grupos era para pesquisar vídeo no youtube, os alunos já conheciam e sabiam procurar, a única dificuldade encontrada foi os computadores da escola, pois não estavam carregando direito os vídeos, assim os alunos escolheram e mandaram os nomes para a bolsista, que baixou os vídeos em casa e levou, eles escolheram dois vídeos um sobre o petróleo e o outro sobre o carvão mineral, pois o tema da equipe era "recursos não renováveis do solo", os vídeos foram passados para a turma.

A equipe que trabalhou o tema "o lixo e o solo" fez entrevistas, gravando áudio com três serventes da escola, e foi montado um vídeo no programa movie maker, com fotos sobre o lixo e o áudio das entrevistas no fundo, o vídeo também foi apresentado para a turma, a entrevista ajudou os alunos a conhecer o trabalho dos 
serventes e saber se todos os alunos da escola fazem sua parte jogando o lixo na lixeira, contribuindo para manter a escola limpa.

Os trabalhos utilizando TIC, por sua facilidade e diversidade de uso, contribuíram para uma maior interação entre a turma, e principalmente como pode ser percebido durante as apresentações para um maior aprendizado, pois os alunos aprendem com mais entusiasmo e dinamismo. Segundo Moran, Masetto e Behrens (2000, p. 5),

\begin{abstract}
A criança aprende a informar-se, a conhecer os outros, o mundo e a si mesma. A relação com a mídia eletrônica é prazerosa e sedutora, mesmo durante o período escolar, a mídia mostra o mundo de outra forma, mais fácil, agradável. A mídia continua educando como contraposto à educação convencional, educa enquanto entretém.
\end{abstract}

Pode-se perceber também a alegria dos alunos em poder utilizar os computadores e o celular em sala de aula, desenvolvendo principalmente a criatividade, sendo que eles puderam criar slides e vídeos, como também a curiosidade, iniciativa e autonomia do aluno em fazer escolhas, pois estiveram envolvidos em todo o processo da pesquisa e montagem do trabalho. Com as apresentações pode-se perceber ainda quais os alunos tinham maior facilidade em falar para a sala, quais eram mais tímidos, quais os que mais estudaram e quais não se prepararam tão bem.

A professora de ciências ficou impressionada com a criatividade dos alunos o que também acabou surpreendendo a bolsista por ser uma turma de $6^{\circ}$ ano.

Pode-se concluir com a pesquisa que o uso de TIC influência de forma positiva no aprendizado dos alunos, segundo autores como Kaieski, Grings e Fetter (2015), Moura e Brandão (2013), as TICs influenciam o aprendizado desde que utilizada com um objetivo e de forma consciente e que os professores não podem ter medo de utiliza-las em sala de aula, pois as TIC podem ser uma grande aliada do professor.

Já por parte dos alunos eles gostam e gostariam de sempre ter as TIC envolvidas nas aulas para que estejam envolvidos com o processo, e possam utilizar algo que já conhecem para ficar mais próximo do conteúdo trabalhado na sala de aula. 


\section{CONCLUSÃO}

A revisão bibliográfica destaca a importância das TICs no processo de aprendizagem dos conteúdos científicos, enfatizando que é um recurso que já faz parte do cotidiano das pessoas. Fica destacado também que os estudantes gostam de usá-las nas aulas, reforçando as pesquisas realizadas por autores como Moura e Brandão (2013), Moran (2000) e Kaieski, Grings e Fetter (2015) que os resultados são positivos com o uso das mesmas. Os autores enfatizam também que alguns professores têm medo de usa-las por falta de conhecimento sobre as tecnologias, até mesmo por achar que elas possam comprometer suas aulas. De acordo com os autores estudados é importante que as escolas e os professores se atualizem para poder acompanhar o ritmo da sociedade onde seus alunos estão inseridos.

Com a aplicação da atividade pode-se perceber que os alunos sentem falta de aulas diferentes. Percebe-se também que eles gostam e se sentem felizes por poderem utilizar tecnologias participando ativamente do processo de ensinoaprendizagem. $O$ fato de terem que ir em busca de algo e colocar em prática, usar a sua criatividade, indicou que é muito importante para o aluno, mostrando que ele é capaz e que toda essa dinâmica, além do aprendizado, contribui na interação entre os colegas de classe.

\section{Agradecimentos}

Nossos agradecimentos especiais à PROPEX - Programa de Pesquisa e Extensão da Unesc pelo apoio financeiro; à professora da Escola que partilhou conosco suas aulas e seus conhecimentos, aos estudantes que generosamente participaram desta investigação. Muito obrigada a todos.

\section{REFERÊNCIAS}

KAIESKI, Naira; GRINGS Jacques Andre; FETTER Shirlei Alexandra. Um estudo sobre as possibilidades pedagógicas de utilização do whatsapp. Novas tecnologias na educação v. 13 no 2, dezembro, 2015.

MORAN, José Manuel; MASETTO, Marcos T.; BEHRENS, Marilda Aparecida. Novas tecnologias e mediação pedagógica. Campinas : Papirus, 2000. 
MOURA, Eliane. BRANDÃO, Edmeilson. $O$ uso das tecnologias digitais na modificação da prática educativa escolar. Revista Cientifica Fazer. Rio Grande do Sul: v 1, no 1, 2013.

SERAFIM, Maria Lucia. SOUSA, Robson Pequeno de. Multimídia na educação: o vídeo digital integrado ao contexto escolar. Disponível em: < http://books.scielo.org/id/6pdyn/pdf/sousa-9788578791247-02.pdf.> Acessado dia 29 de fevereiro de 2016.

VALLENTE, José Armando. Formação de professores: diferentes abordagens pedagógicas. In.: José Armando Vallente (org). O computador na sociedade do conhecimento. Campinas, SP. UNICAMP-NIED, 1999. 